\title{
Congenital microvillous atrophy: specific diagnostic features
}

\author{
A D PHILLIPS, P JENKINS, F RAAFAT, AND J A WALKER-SMITH \\ Queen Elizabeth Hospital for Children, London
}

Summary Proximal small intestinal and colonoscopic mucosal biopsies from two children with the intractable diarrhoea of infancy syndrome were examined by electron microscopy. Microvillous involutions were found in the small and large bowel of both patients. We suggest that this is a specific diagnostic finding for congenital microvillous atrophy, a distinct disorder within the intractable diarrhoea syndrome which has an extremely poor prognosis.

In 1968 Avery et al $^{1}$ reported 20 children with the syndrome of intractable diarrhoea of infancy. Although diagnoses were made in many of the patients, a group of eight children remained where no diagnosis was possible, treatment was ineffective, and mortality was high. Later studies have underlined these findings and confirmed the lack of specific diagnoses, the major difficulties of patient management, and the high mortality rate within this syndrome. ${ }^{2-5}$

In 1978 Davidson et al drew attention to patients suffering intractable diarrhoea of infancy who showed hypoplastic villous atrophy on small intestinal biopsy. Electron microscopy in one patient showed a distinctive ultrastructural abnormality of the microvilli of the enterocytes. This observation was repeated in three patients in two studies in France $^{78}$ and was termed congenital microvillous atrophy. ${ }^{7}$ We describe two further cases and suggest that the ultrastructural changes are specific diagnostic features of a disorder within the syndrome of intractable diarrhoea of infancy.

\section{Case histories}

Case 1. This girl was born at 37 weeks' gestation after a normal pregnancy, and weighed $2.5 \mathrm{~kg}$. She was breast fed and given supplementary formula milk but developed diarrhoea on day two of life. Stool losses increased and persisted despite stopping oral feeding. She was transferred to Queen Elizabeth Hospital for Children on day 42. On examination she weighed $2 \mathrm{~kg}$ and was $5 \%$ dehydrated. There were no other abnormalities. She was found to have secretory diarrhoea with a stool sodium of $91 \mathrm{mmol}(\mathrm{mEq}) / \mathrm{l}$. Parenteral nutrition was begun and she gained weight. Serum immunoglobulin estimation initially showed raised $\operatorname{IgA} 41$ $\mathrm{IU} / \mathrm{ml}$ (normal 2 to $20 \mathrm{IU} / \mathrm{ml}$ ) and $\mathrm{IgM} 82 \mathrm{IU} / \mathrm{ml}$ (normal 10 to $50 \mathrm{IU} / \mathrm{ml}$ ), with a normal IgG value. At 4 months of age her IgG concentration had fallen to $37 \mathrm{IU} / \mathrm{ml}$ (normal 40 to $128 \mathrm{IU} / \mathrm{ml}$ ), and $\mathrm{IgA}$ and IgM values had returned to within the normal ranges. Serum zinc was initially $4.4 \mathrm{mmol} / \mathrm{l}(0.67$ $\mathrm{mg} / 100 \mathrm{ml}$ ) (normal 12.6 to $25.8 \mathrm{mmol} / \mathrm{l}(1.9$ to 3.9 $\mathrm{mg} / 100 \mathrm{ml}$ )) but rose to normal values as nutrition improved. Gastrointestinal hormone concentrations (vasoactive intestinal polypeptide, pancreatic polypeptide, glucagon, somatostatin, and neurotensin) were normal but gastrin was marginally raised at 59 and $80 \mathrm{pmol} / \mathrm{l}$ on two occasions (normal less than $40 \mathrm{pmol} / \mathrm{l})$.

Slow introduction of oral feeding, using cows' milk-free feeds based on a comminuted chicken formula, failed because of dramatic increases in stool losses whenever oral feeds were given. Other unsuccessful treatments included loperamide (up to $1 \mathrm{mg} / \mathrm{kg} /$ day), oral disodium cromoglycate, adrenocorticotrophic hormone, and prednisolone. Small intestinal biopsies were performed at 3 and 4 months of age. She died at 6 months of age.

Case 2. This girl was born at 34 weeks' gestation after an uneventful pregnancy, weighed $2 \cdot 2 \mathrm{~kg}$, and was bottle fed. Her mother had diarrhoea on the day of delivery and this directed investigation of the patient's diarrhoea (which developed at age 4 days) towards an infective cause, but no pathogen, bacterial or viral, was found. Diarrhoea continued unabated, despite a cows' milk-free formula, and parenteral nutrition was begun. Persistent acidosis developed and although the child was given nil by 
mouth, stool losses increased. On admission to Queen Elizabeth Hospital for Children at age 56 days, she was an active but poorly nourished infant weighing less than her birthweight. There were no other physical abnormalities. She had a secretory diarrhoea with a stool sodium of $93(\mathrm{mEq}) \mathrm{mmol} / \mathrm{l}$. Parenteral nutrition was continued while further investigations were done. Stool losses decreased remarkably after loperamide treatment $(0 \cdot 1 \mathrm{mg} / \mathrm{kg}$ day) as long as she was given nil by mouth. At 9 weeks of age she had a raised serum $\operatorname{IgM}$ value of $124 \mathrm{IU} / \mathrm{ml}$ (normal 10 to $50 \mathrm{IU} / \mathrm{l}$ ) but a low $\mathrm{IgG}$ of 22 $\mathrm{IU} / \mathrm{ml}$ (normal 30 to $110 \mathrm{IU} / \mathrm{ml}$ ). The concentration of IgG returned to normal by 3 months of age but IgM remained raised, probably related to a series of catheter associated infections. The serum IgA concentration was normal. Her serum zinc value was initially low at 3 months but was normal at 4 months. Gut hormone values were normal except for enteroglucagon which was raised at $455 \mathrm{pmol} / \mathrm{l}$ while being fed comminuted chicken hourly.

Serum gut autoantibodies were not detected. Several attempts to introduce oral feeding using a casein hydrolysate formula at first and then comminuted chicken based feed were unsuccessful. Other treatments were parenteral cimetidine, which produced electrolyte imbalance due to proximal renal tubular problems, and oral dexamethasone, which was also unsuccessful. Small intestinal biopsies were performed at 3, 4, and 6 months of age to evaluate the response to changes in treatment. She died at 6 months of age.

Normal investigation in both infants included sweat electrolytes, T lymphocyte function, opsonisation, serum amino acids, serology for rubella and cytomegalovirus, chromosomes, and thyroid function. Urinary catecholamine concentrations were also normal. Colonoscopies were performed in both patients and the colonic mucosal histology was normal, although ultrastructural abnormalities were detected.

\section{Methods}

Proximal small intestinal biopsies were performed (with informed parental consent) using a double port modification of the paediatric Crosby capsule. ${ }^{9}$ Specimens were processed for light and electron microscopy, and for disaccharidase estimations. ${ }^{10}$ Colonoscopic biopsies, taken during routine endoscopic examination, were studied by light and electron microscopy.

For routine histological examination specimens were fixed in formol-saline and embedded in ester wax. Five micrometre thick sections were stained with haematoxylin and eosin and with periodic
acid-Schiff reagent. Samples for electron microscopy were fixed in $3 \%$ glutaraldehyde in $0.1 \mathrm{M}$ phosphate buffer, postfixed in $1 \%$ aqueous osmium tetroxide, dehydrated in 2,2 dimethoxy propane (Aldrich Chemicals) and embedded in TAAB resin (TAAB Laboratories, England). Sections were double stained with $2 \%$ aqueous uranyl acetate and lead citrate. ${ }^{11}$

Care was taken, for both light and electron microscopy, to ensure that sections were taken perpendicularly to the muscularis mucosae.

\section{Results}

\section{Small intestinal biopsies.}

\section{Light microscopy}

In both patients biopsies showed the features of hypoplastic villous atrophy, that is villous atrophy without crypt hypertrophy, producing a thin mucosa (Fig. 1). Periodic acid-Schiff staining of the mucosa showed an absence of the usual brush border staining pattern with positive staining material present within the apical cytoplasm of enterocytes (Fig. 2).

\section{Electron microscopy}

In both patients transmission electron microscopy showed similar appearances. Surface epithelial cells were severely abnormal in terms of decreased cell height, shortened and infrequent microvilli, increased polyribosomes, and increased secondary

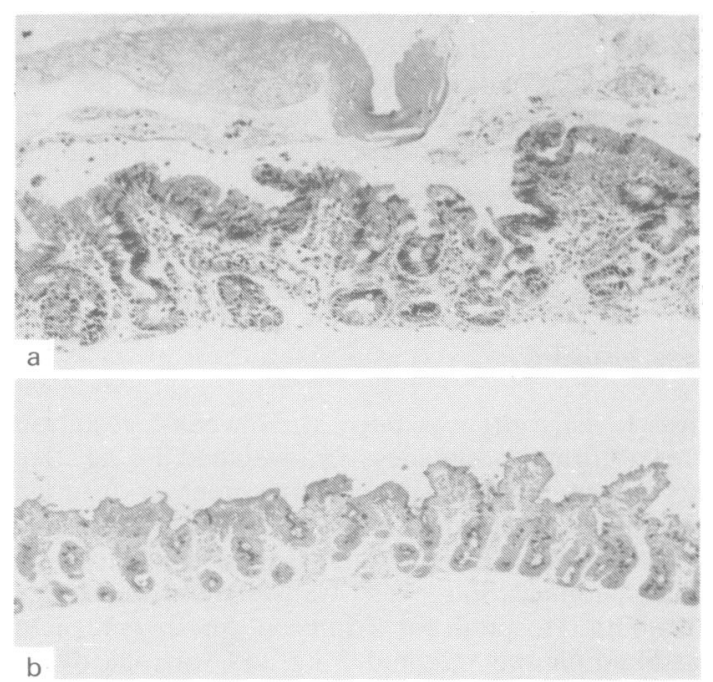

Fig. 1 Proximal small intestinal mucosae showing hypoplastic villous atrophy in (a) case 1 (haematoxylin and eosin, $\times 95$ ) and $(b)$ case 2 (periodic acid Schiff, $\times 60$ ). 


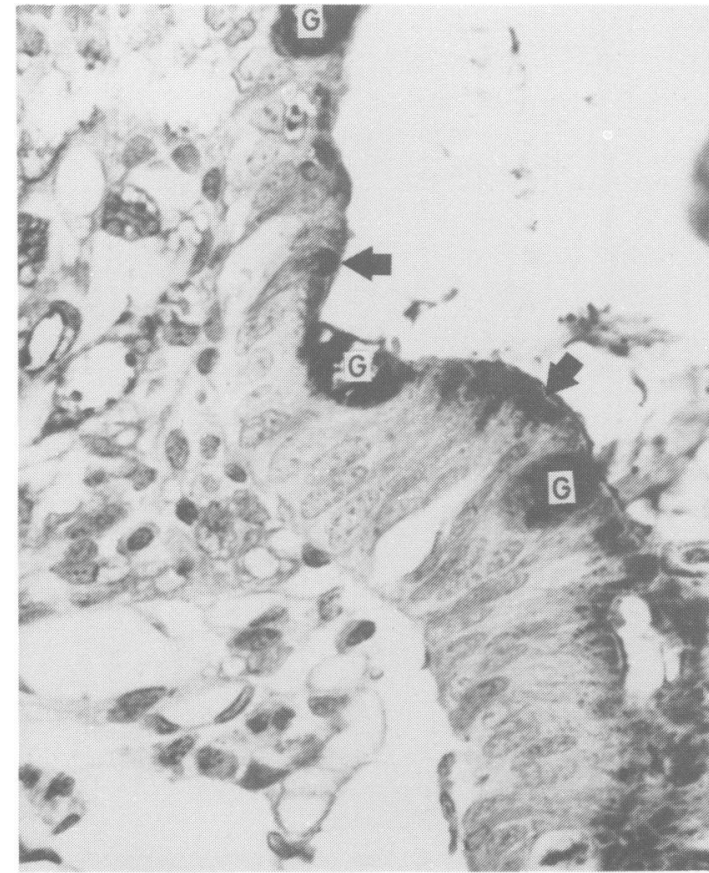

Fig. 2 Case 2: abnormal periodic acid Schiff staining of apical epithelial cytoplasm (arrows); goblet cells stain normally $(G)$. (Small intestine, $\times 940)$.

lysosomal and cytolysosomal bodies. Additionally, membrane bound bodies containing obvious microvilli were found. These microvillous involutions were seen in the most apical part of the cytoplasm (Fig. 3a) and represent the diagnostic ultrastructural feature of this disorder. Although readily identified, they were not seen in every surface epithelial cell and were not observed in crypt epithelium.

Crypt epithelium was distinguished by the presence of increased numbers of secretory granules in an otherwise normal appearance (Fig. 3b). There seemed to be a rapid demise, in morphological terms, from the relatively normal crypt cells to the severely abnormal surface epithelium.

Disaccharidases. All disaccharidase results were abnormally low (Table 1).

Colonoscopic biopsies. Light microscopy appearances were within normal limits. Electron microscopy showed surface exposed colonocytes with shortened microvilli and increased number of mucigen granules. Microvillous involutions were again present (Fig. 4) but were not as frequently seen as in the small intestinal biopsies. Crypt
Table 1 Disaccharidase enzyme activities ( $\mu$ mol substrate cleaved/minute per $g$ wet weight)

\begin{tabular}{llllr}
\hline & Case I & Case 2 & \multicolumn{1}{c}{$\begin{array}{l}\text { Normal } \\
\text { range }\end{array}$} \\
\hline Age (months) & 4 & 3 & 6 & \\
Lactase & $0 \cdot 6$ & $0 \cdot 9$ & $1 \cdot 2$ & $2 \cdot 1-12 \cdot 5$ \\
Maltase & $3 \cdot 0$ & $9 \cdot 9$ & $7 \cdot 5$ & $12 \cdot 6-39 \cdot 6$ \\
Sucrase & $1 \cdot 0$ & $2 \cdot 9$ & $2 \cdot 4$ & $3 \cdot 8-14 \cdot 5$ \\
\hline
\end{tabular}

Table 2 Ultrastructural features in congenital microvillous atrophy
(a) Enterocyte
(1) Severely abnormal exposed surface epithelium
(2) Short and depleted microvilli
(3) Microvilli within involutions of apical membrane
(b) Crypt cells
(1) Well preserved microvilli
(2) Increased electron dense secretory (small bowel) or mucigen (large bowel) granules in the upper crypt

epithelium seemed relatively normal, apart from an increase in mucigen granules.

The ultrastructural features of congenital microvillous atrophy are summarised in Table 2 .

\section{Discussion}

Intractable diarrhoea of infancy is a severe disorder in paediatric gastroenterology presenting major problems of diagnosis and management. It is a heterogeneous syndrome including a wide range of diagnoses, but leaving an important group with intractable diarrhoea of unknown origin. Electron microscopic examination of proximal small intestinal mucosal biopsies from this group of children has shown the unusual and striking abnormality of microvillous involutions in the surface epithelium.

The finding of microvillous involutions was first reported by Davidson et at in one of a series of five patients who all showed hypoplastic villous atrophy. To date, including the two patients in this paper and those described from France, ${ }^{78}$ six patients have been described in the published reports. All six were suffering from intractable diarrhoea of infancy, in all the onset of symptoms was at birth or shortly afterwards, all had a secretory diarrhoea, attempts at reintroducing oral feeds caused severe increases in stool losses, and despite treatment, all have died.

Although the five patients described by Davidson ${ }^{6}$ showed clinical similarities, the finding of microvillous involutions in one patient is so distinctive that we suggest this should be considered as a discrete disease entity within the syndrome of intractable diarrhoea of infancy. Davidson ${ }^{6}$ indicated that the 

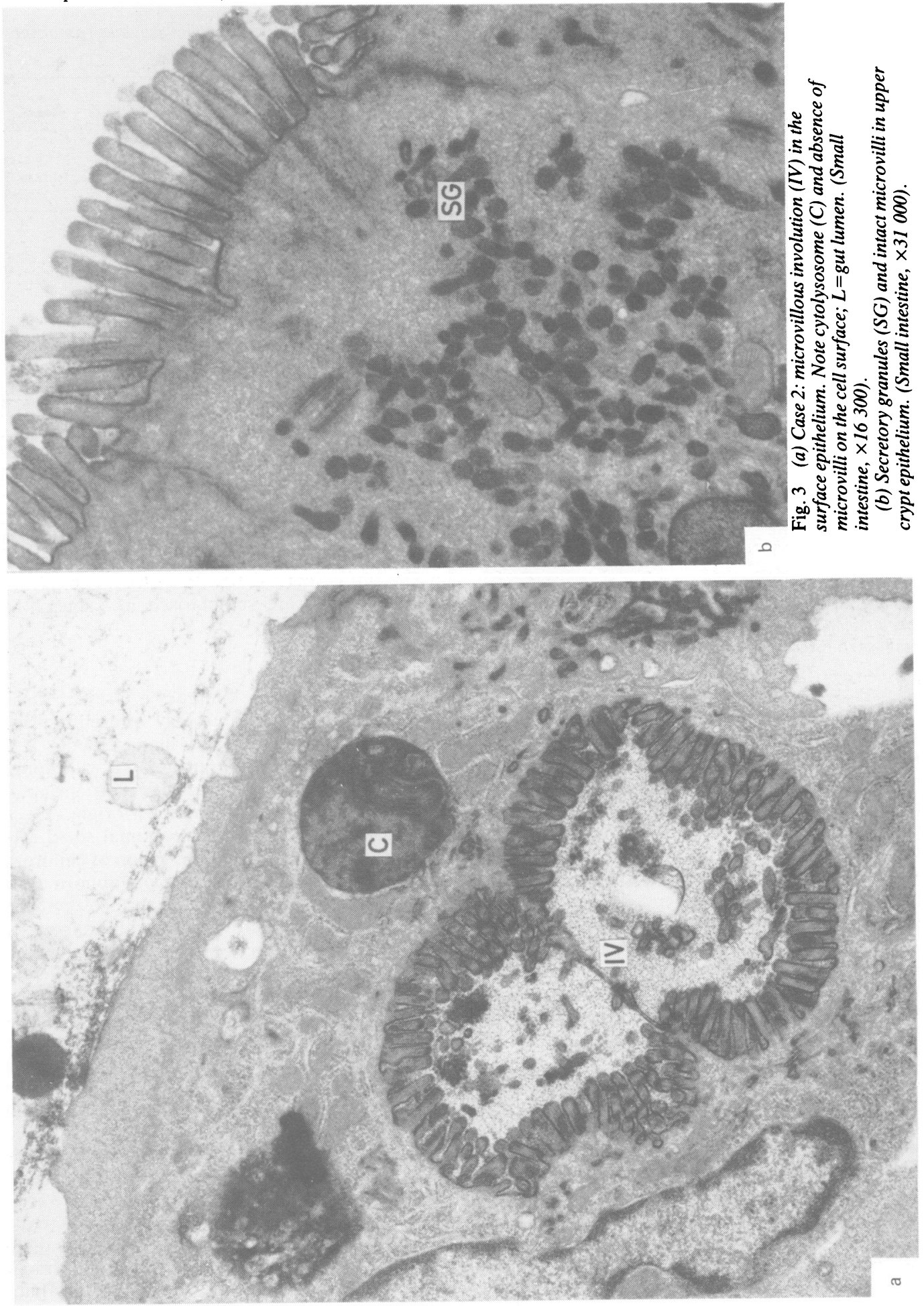


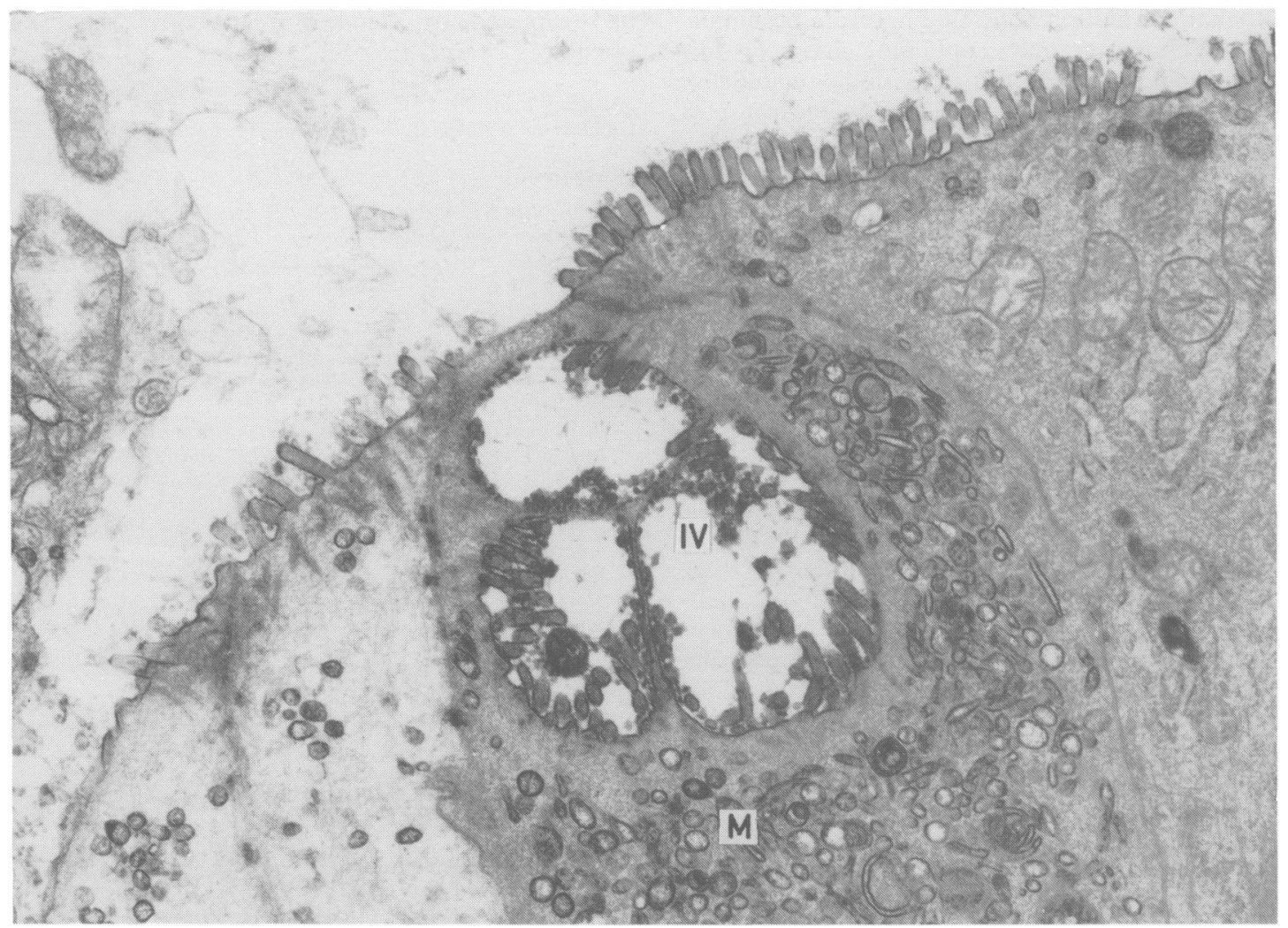

Fig. 4 Case 1: microvillous involution (IV) in the surface epithelium. M=mucigen granules (Colon, $\times 16400)$.

patients represented more than one disease state and was unable to find microvillous involutions in small intestinal biopsies from two of the three patients studied by electron microscopy.

Electron microscopy is routinely applied to proximal small intestinal biopsies at this hospital and the two children described here are the only patients to show microvillous involutions, thereby implying a specific defect. Other children with intractable diarrhoea of infancy, in whom no diagnosis has been made, have not shown microvillous involutions, reflecting the experience of Davidson et at and indicating that more than one disease state is present in this group of children.

Davidson et $a t^{6}$ used the term 'familial enteropathy' to describe their five patients. We consider "congenital microvillous atrophy" a better diagnostic term to apply to those patients showing microvillous involutions, although they all probably fall within the familial enteropathy syndrome.

The six patients reported with congenital microvillous atrophy may not reflect its real incidence as electron microscopy is not always used to examine small bowel biopsies from patients with intractable diarrhoea. Periodic acid-Schiff staining of histological sections may show findings suggestive of this disorder and offers a method of retrospective analysis. This presumes, of course, that a small intestinal biopsy is performed in cases of intractable diarrhoea, a prerequisite for diagnosis. It is possible to reprocess wax-embedded tissue for ultrastructural analysis which, although not providing ideal material for study, may allow a firm diagnosis of congenital microvillous atrophy to be made.

It seemed that the secretory diarrhoea was not present before birth but was precipitated by oral feeding in these patients and the patient described by Davidson ${ }^{6}$ (the three patients described from France have only been reported in abstract form, ${ }^{78}$ so full information concerning their clinical courses is not yet available). This observation and the appearance of near normal crypt epithelium in a hypoplastic mucosa, suggests an abnormality affecting only mature enterocytes or the process of 
epithelial maturation. The finding of an accumulation of secretory granules containing glycocalyx-like material and the abnormal periodic acid-Schiff staining pattern suggest an inability to transport substances onto the brush border. Schmitz ${ }^{12}$ described the abnormal localisation of sucrase in the apical epithelial cytoplasm in their patient, again indicating a defect in transport from the cytoplasm to the brush border. Davidson et at provided histochemical and ultrastructural evidence that the microvillous involutions were being degraded by lysosomal enzymes. The lack of the full complement of microvillous-associated substances may render the microvilli prone to autophagocytosis and lysosomal degeneration.

Treatment, aimed at stimulating enterocyte growth and development has been unsuccessful. We tried cimetidine, because of its reported trophic effect on the gut, ${ }^{13}$ and dexamethasone. Other treatments have included oral cholestyramine, pentagastrin, and somatostatin. The high enteroglucagon value in patient 2 also indicates that increasing the stimulus for cell growth and development is not a sufficient means for correcting this disorder. Furthermore, our finding that microvillous involutions are present in the large bowel shows that small and large bowel are both affected and that congenital microvillous atrophy is not a discrete lesion of the small intestine. Presumably there is a cellular deficiency in the ability to respond to trophic stimuli. Future efforts should be aimed at understanding this process with the hope that an effective treatment for the disorder will result. An essential requirement for understanding the disease process is to obtain a precise diagnosis. In congenital microvillous atrophy this is only possible with transmission electron microscopy and we would recommend that either small or large bowel biopsies, or both from children with intractable diarrhoea of infancy should be examined by electron microscopy whenever possible.

We thank Professor Bloom (Royal Postgraduate Medical School, Hammersmith Hospital) for performing the enteroglucagon assay.

\section{References}

1 Avery GB, Villavicencio O, Lilly JR, Randolph JG. Intractable diarrhoca in early infancy. Pediatrics 1968;41:712-22.

${ }^{2}$ Hyman CJ, Reiter J, Rodnan J, Drash AL. Parenteral and oral alimentation in the treatment of the non-specific protracted diarrhoeal syndrome of infancy. J Pediatr 1971;78:17-29.

${ }^{3}$ Lloyd-Still JD, Shwachman H, Filler RM. Protracted diarrhoea of infancy treated by intravenous alimentation. I. Clinical studies of 16 infants. Am J Dis Child 1973;125:358-64.

${ }^{4}$ Larcher VF, Shepherd R, Francis DEM, Harries JT. Protracted diarrhoea in infancy. Analysis of 82 cases with particular reference to diagnosis and management. Arch Dis Child 1977;52:597-605.

5 Candy DCA, Larcher VF, Cameron DJS, et al. Lethal familial protracted diarrhoea. Arch Dis Child 1981;56:15-23.

6 Davidson GP, Cutz E, Hamilton JR, Gall DG. Familial enteropathy: a syndrome of protracted diarrhoea from birth, failure to thrive, and hypoplastic villous atrophy. Gastroenterology 1978;75:783-90.

7 Schmitz J, Ginies JL, Arnaud-Battandier F, et al. Congenital microvillous atrophy, a rare cause of neonatal intractable diarrhoea. Pediatr Res 1982;16:1014.

${ }^{8}$ Goutet JM, Boccon-Gibod L, Chatelet F. Ploussard JP, Navarro J, Polonovski CI. Familial protracted diarrhoea with hypoplastic villous atrophy: report of two cases. Pediatr Res 1982;16:1045.

${ }^{9}$ Kilby A. Paediatric small intestinal biopsy capsule with two ports. Gut 1976;17:158-9.

11 Phillips AD, Avigad S, Sacks J, Rice SJ, France NE, WalkerSmith JA. Microvillous surface area in secondary disaccharidase deficiency. Gut 1980;21:44-8.

1 Reynolds ES. The use of lead citrate at high $\mathrm{pH}$ as an electron opaque stain in electron microscopy. J Cell Biol 1963;17:208-12.

${ }^{12}$ Schmitz J. A pathological condition due to congenital disorganisation of the brush border. In: Brush border membranes. CIBA Foundation Symposium 1983. London: Pitman, 1983: 245-52.

13 Fisher SE, Boyle JT, Holtzapok I. Chronic protracted diarrhoea and jejunal atrophy in an infant. Dig Dis Sci 1981;46:181-6.

Correspondence to Mr A D Phillips, Queen Elizabeth Hospital for Children, Hackney Road, London E2 8PS.

Received 19 November 1984 